\title{
Influence of masticatory fatigue on the fracture resistance of the pulpless teeth restored with quartz-fiber post-core and crown
}

\author{
Er-Min Nie ${ }^{1, *}$, Xia-Yun Chen ${ }^{2, *}$, Chun-Yuan Zhang ${ }^{1, *}$, Li-Li Qi ${ }^{1}$ and Ying-He Huang ${ }^{3}$
}

To investigate whether masticatory fatigue affects the fracture resistance and pattern of lower premolars restored with quartz-fiber post-core and full crown, 44 single rooted lower premolars recently extracted from orthodontic patients were divided into two groups of 22 each. The crowns of all teeth were removed and endodontically treated and then restored with quartz-fiber post-core and full crown. Twenty-two teeth in one group were selected randomly and circularly loaded at $45^{\circ}$ to the long axis of the teeth of $127.4 \mathrm{~N}$ at a $6 \mathrm{~Hz}$ frequency, and the other group was not delivered to cyclic loading and considered as control. Subsequently, all teeth in two groups were continually loaded to fail at $45^{\circ}$ to the long axis of the teeth at a crosshead speed of $1 \mathrm{~mm} \cdot \mathrm{min}^{-1}$. The mean destructive force values were $(733.88 \pm 254.99)$ and $(869.14 \pm 280.26) \mathrm{N}$ for the experimental and the control group, respectively, and no statistically significant differences were found between two groups $(P>0.05)$. Bevel fracture and horizontal fracture in the neck of root were the major fracture mode of the specimens. Under the circumstances of this study, it seems that cyclic loading does not affect the fracture strength and pattern of the quartz-fiber post-core-crown complex.

International Journal of Oral Science (2012) 4, 218-220; doi:10.1038/ijos.2012.78; published online 10 January 2013

Keywords: fracture resistance; masticatory fatigue; pulpless teeth; quartz-fiber

\section{INTRODUCTION}

There are two methods currently used for assessing the fracture resistance of dental restoration: the static fracture test and dynamic fracture test (i.e., fatigue fracture test). ${ }^{1}$ A static test is often regarded as clinically less relevant, since such abrupt loading never occurs. However, dynamic fatigue testing is claimed to better predict the clinical situation and has been considered as the standard to assess or predict the influence of mouth-motion fatigue on dental restoration. Since special equipment and complexity of the operation needed for cyclic loading, many previous works studied the biomechanical performance under static loads. ${ }^{2-4}$ A structured literature review found that $59 \%$ of the included studies used static loading and only $15 \%$ of the studies performed thermocycling and mechanical loading. ${ }^{5}$

Although it seems that cyclic loading is more realistic as in clinic, the effect of cyclic loading on the post-core-crown complex remains controversial. Sterzenbach founded that maximum load capacities of the same post-material obtained from gradual dynamic loading did not differ significantly from that of linear compressive loading or of chewing simulation in their foregoing study. ${ }^{6}$ However, their subsequent study reported that dynamic loading prior to load-to-fracture testing of the complete restorative complex significantly decreased maximum load capability inconsequently. ${ }^{1}$ Similar results were reported that when fiber posts-cores complex were subjected to cyclic loading, decreases in microtensile bond strength were observed. ${ }^{7}$

Therefore, the present study aimed to evaluate the effect of cyclic loading on the fracture resistance and pattern of quartz-fiber postcore crown restorations. The null hypothesis was that it has no effect on the fracture resistance and pattern of quartz-fiber post-core crown restorations.

\section{MATERIALS AND METHODS}

Forty-four adult lower premolar teeth with single-root canals extracted for orthodontic treatment were selected for this study, which were free from caries, fractures and crown discoloration by visual inspection.

Modeling and grouping

Forty-four selected premolars were divided into two groups of 22 each. Bucco-palatal and mesio-distal dimensions and root lengths of all the selected teeth were measured using calipers, the statistic analysis was carried out at a $95 \%$ level of confidence, and there were no significant differences $(P>0.05)$ among groups in terms of bucco-palatal and mesio-distal dimensions. Coronal sections of all teeth were removed with a low speed diamond saw at the approximately $1.5 \mathrm{~mm}$ above the cemento-enamel junction and then endodontically instrumented, and

\footnotetext{
${ }^{1}$ Department of Prosthodontics, The First Affiliated Hospital, Sun Yat-Sen University, Guangzhou, China; ${ }^{2}$ Department of Prosthodontics, The Third Affiliated Hospital, Sun YatSen University, Guangzhou, China and ${ }^{3}$ Department of Stomatology, Taishan People's Hospital, Taishan, China

*These three authors contributed equally.

Correspondence: Dr CY Zhang, Department of Prosthodontics, The First Affiliated Hospital, Sun Yat-Sen University, Guangzhou 510080, China

E-mail: zhangcy1902@126.com
}

Received 19 July 2012; accepted 19 November 2012 
the root canals were obturated with gutta-percha, then were stored in distill water for 3 days.

Post space was prepared to two-thirds of the root length using a preshaping and finishing drill (D.T. \#2; Bisco Inc., Schaumburg, IL, USA), and then was etched with $32 \%$ orthophosphoric acid (Bisco, Schaumburg, IL, USA) for $20 \mathrm{~s}$, and then washed with a water syringe repeatedly and gently air-dried. A quartz fiber post (ASTHETI-PLUS \#2; Bisco Inc., Schaumburg, IL, USA) was luted into the post space with a dual-cured resin cement (Duo-Link; Bisco Inc., Schaumburg, IL, USA) in combination with All Bond 2 (Bisco Inc., Schaumburg, IL, USA). Core build-up (Bisco Inc., Schaumburg, IL, USA) procedures were performed to restore the core for shaping. The shape of the core portion is around $6 \mathrm{~mm}$ high with a $3-6^{\circ}$ taper and $1 \mathrm{~mm}$ shoulder was created. Cobalt-chromium metal crowns were fabricated and luted by glass ions (3M ESPE, 3M, Seefeld, Germany). At the occlusal surface, the positioning groove has been reserved for loading from mesial to distal at the central developmental groove.

\section{Cyclic loading}

Twenty-two teeth in one group were selected randomly and circularly loaded as the experimental group. Self-curing acrylics was poured into a metal casting mold base (diameter $3 \mathrm{~cm}$, height $3 \mathrm{~cm}$ ) and the root was wrapped with a thin layer of wax and then embedded into the base up to $2 \mathrm{~mm}$ below the cemento-enamel junction before the resin setting. Once the acrylic resin was totally set, the root was taken out, and the wax on the root surface has been scraped off. Then, the high-fluidity silicone rubber impression material (3M ESPE) has been poured into the base for inserting the restoration in until complete setting of silicone rubber, in order to simulate the periodontal ligament. All specimens were stored at $37{ }^{\circ} \mathrm{C}$ for 3 days prior to the cyclic load test.

The test specimens were placed on the cyclic loading equipment with a loading crosshead ( $2 \mathrm{~mm}$ width). A $45^{\circ}$ oblique cyclic load of $127.4 \mathrm{~N}$ at $6 \mathrm{~Hz}$ was applied at the reserved positioning groove on the occlusal surface with a spherical-type contact. Totally 1.2 million cycles of load was applied to each specimen for simulating the occlusional movement during 5 years. At the end of loading test, the specimens were taken out from the base and stored in distill water for next use.

\section{Static loading}

All the specimens of experimental group and the control group were embedded in a block base $(200 \mathrm{~mm} \times 150 \mathrm{~mm} \times 30 \mathrm{~mm})$ by self-cure acrylic resin up to $2 \mathrm{~mm}$ below the cemento-enamel junction. A $45^{\circ}$ oblique compressive load was applied to the specimen simulating the direction of the lateral occlusional force on the lower premolars, with a crosshead speed of $1 \mathrm{~mm} \cdot \mathrm{min}^{-1}$ using a MTS-858 universal testing machine (MTS Inc., Arlington, VA, USA). The loading site was at the reserved positioning groove on the occlusal surface.

\section{Observation criteria}

The fracture loads and fracture patterns of post-core of pulpless teeth subjected to the $45^{\circ}$ oblique loading were recorded.

\section{Statistic analysis}

Fracture loads of the experimental and control group were compared using one-way analysis of variance (ANOVA) at a 95\% level of confidence by SPSS 13.0 (SPSS Inc., Chicago, IL, USA).

\section{RESULTS}

The fracture resistance of the experimental and control group are summarized in Table 1. There is no significant difference between two groups regarding to the fracture resistance force $(P=0.105>0.05)$.
Table 1 Fracture resistance force of experimental groups

\begin{tabular}{lccc}
\hline & & \multicolumn{2}{c}{ Fracture resistance force/N } \\
\cline { 3 - 4 } Groups & $n$ & Mean \pm s.d. & Range \\
\hline Experimental group & 22 & $733.88 \pm 254.99$ & $324.52-1258.61$ \\
Control group & 22 & $869.14 \pm 280.26$ & $408.61-1315.84$ \\
\hline
\end{tabular}

All specimens of two groups displayed favorable fractures except a vertical fracture in experimental group. Bevel fracture and horizontal fracture in the neck of root are the major fracture types in both groups. No fractures were seen in the middle or apical third of the roots.

\section{DISCUSSION}

The inclusion of the fatigue analysis allows for a more realistic study that takes into account the dynamic nature of masticatory forces. In this study, the loading force in fatigue test was chosen as $13 \mathrm{~kg}$, which was in the range of ordinary chewing force of an adult $(7-15 \mathrm{~kg}) .^{8}$ Totally 1.2 million cycle of load was applied to each specimen for simulating the chewing movement during 5 years. The frequency of cyclic loading at $6 \mathrm{~Hz}$ in this study situated between 2 and $8 \mathrm{~Hz}$ and the $45^{\circ}$ oblique loading in static test have been already applied by many researchers. ${ }^{1,7,9-10}$ Such study approach is internationally well acknowledged.

No significant difference of fracture resistance was found after cyclic loaded in this study. This implies that the quartz-fibre post-core system has very good fracture resistance even after 1.2 million fatigue loading cycles. The effectiveness of such restorations has been mainly ascribed to the more biomechanical behaviour of quartz-fibrereinforced composite posts. It possesses the similar modulus of elasticity to that of the radicular dentin, which allows the post keeping close contact under the force and function as a integrity unit when bonded by resin cement. ${ }^{11-12}$ Thus, the stress is homogenously transferred from the post to the dentin and reduce the accumulation of fatigue stress. ${ }^{13-14}$ This homogeneous characteristics of quartz-fibre postcomposite resin core complex make it advantageous when compared with metal posts and other tooth-colored posts. ${ }^{15-17}$ Similar results showed that there was no significant difference in adhesion strength before and after cyclic loading for fiber-post restoration, while for ceramic post group, there was significant difference in adhesion strength before and after cyclic loading. ${ }^{18}$

Additionally, adhesive bonding which begins by acid-etching increases the premeability of resin to detin and enamel, ${ }^{19-20}$ and it may increase the durability of resin-dentin bonds, subsequently reinforced the resistannce of quartz-fibre post-core-crown complex. Tam et al. ${ }^{21}$ has reported that the fracture resistance of the dentin/ composite interface was higher when the dentin surface was conditioned with acid and subsequently air-dried than not conditioned with acid. ${ }^{21}$ This reinforcement may be confirmed by the present study, and the tooth structure and restorative materials together exhibit good fracture resistance. On the other hand, a standardized silicon layer simulating periodontal ligament was created to allow limited freedom of movement, which may have a buffer effect and bate fatigue stress accumulation. $^{22}$

Furthermore, the presence of a $1.0 \mathrm{~mm}$ ferrule in this study may contribute to the whole performance of quartz-fibre post-core-crown complex even after cyclic loading. It has been stated that providing an adequate ferrule lowers the impact of the post and core system, luting agents and the final restoration on tooth performance. ${ }^{23}$ And an amount of coronal dentin significantly increases the fracture resistance 
of endodontically treated teeth and prevention of root fracture of endodontically treated teeth. ${ }^{24-25}$ Moreover, when the ferrule effect is present, stresses are redistributed in the outer surface regions of the coronal third of the root; thus, a possible fracture in this area can be repairable. ${ }^{26}$ This findings may explain the major fracture located in the neck of tooth and exhibted favorable fracture patter in the present study.

Within the limitations of this study, no significant differences were found for their fracture resistance and pattren of the quartz-fiber postcore-crown complex before and after cyclic loading, and the quartzfiber post-core and crown restoration exhibit a good fatigue resistance.

\section{ACKNOWLEDGMENTS}

This experiment was supported by the Guangdong Province Science and Technology Commission (2008B080703019, 2011B080701010 and 2011B080701086).

1 Sterzenbach G, Rosentritt M, Frankenberger R et al. Loading standardization of postendodontic restorations in vitro: impact of restorative stage, static loading, and dynamic loading. Oper Dent 2012; 37(1): 71-79.

2 Bijelic J, Garoushi S, Vallittu PK et al. Fracture load of tooth restored with fiber post and experimental short fiber composite. Open Dent J 2011; 29(5): 58-65.

3 Fokkinga WA, Kreulen CM, Le Bell-Rönnlöf AM et al. Fracture behavior of structurally compromised non-vital maxillary premolars restored using experimental fiber reinforced composite crowns. Am J Dent 2006; 19(6): 326-332.

$4 \mathrm{Kim} \mathrm{YH}$, Lee JH. Influence of modification in core building procedure on fracture strength and failure patterns of premolars restored with fiber post and composite core. J Adv Prosthodont 2012; 4(1): 37-42.

5 Naumann M, Metzdorf G, Fokkinga W et al. Influence of test parameters on in vitro fracture resistance of post-endodontic restorations: a structured review. J Oral Rehabil 2009; 36(4): 299-312.

6 Naumann M, Sterzenbach G, Pröschel P. Evaluation of load testing of postendodontic restorations in vitro: linear compressive loading, gradual cycling loading and chewing simulation. J Biomed Mater Res B Appl Biomater 2005; 74(2): 829-834.

7 Albaladejo A, Osorio R, Aguilera FS et al. Effect of cyclic loading on bonding of fiber posts to root canal dentin. J Biomed Mater Res B App/ Biomater 2008; 86(1): 264-269.

8 Anderson DJ. Measurement of stress in mastication. I. J Dent Res 1956; 35(5): 664-670.

9 Hayashi M, Sugeta A, Takahashi $Y$ et al. Static and fatigue fracture resistances of pulpless teeth restored with post-cores. Dent Mater 2008; 24(9): 1178-1186.

10 Leong EW, Choon Tan KB, Nicholls JI et al. The effect of preparation height and luting agent on the resistance form of cemented cast crowns under load fatigue. J Prosthet Dent 2009; 102(3): 155-164.
11 Grandini S, Goracci C, Monticelli F et al. Fatigue resistance and structural characteristics of fiber posts: three-point bending test and SEM evaluation. Dent Mater 2005; 21(2): 75-82.

12 Vichi A, Grandini S, Davidson CL et al. An SEM evaluation of several adhesive systems used for bonding fiber posts under clinical conditions. Dent Mater 2002; 18(7): 495502.

13 Giachetti L, Scaminaci Russo D, Baldini M et al. Push-out strength of translucent fibre posts cemented using a dual-curing technique or a light-curing self-adhering material. Int Endod J 2012; 45(3): 249-256.

14 Mosharraf R, Hashemi Z, Torkan S. In vitro study of transverse strength of fiber reinforced composites. J Dent (Tehran) 2011; 8(3): 101-106.

15 Rosa R, Hwas A, Melo D et al. Fracture strength of endodontically treated teeth restored with different strategies after mechanical cycling. Gen Dent 2012; 60(2): e62-e68.

16 Bolhuis P, de Gee A, Feilzer A. Influence of fatigue loading on four post-and-core systems in maxillary premolars. Quintessence Int 2004; 35(8): 657-667.

17 Akkayan B, Gülmez T. Resistance to fracture of endodontically treated teeth restored with different post systems. J Prosthet Dent 2002; 87(4): 431-437.

18 Bottino MA, Baldissara P, Valandro LF et al. Effects of mechanical cycling on the bonding of zirconia and fiber posts to human root dentin. J Adhes Dent 2007; 9(3) 327-331.

19 Gwinnett AJ, Matsui A. A study of enamel adhesives. The physical relationship between enamel and adhesive. Arch Oral Biol 1967; 12(12): 1615-1620.

20 Pashley $\mathrm{DH}$, Ciucchi B, Sano $\mathrm{H}$ et al. Permeability of dentin to adhesive agents. Quintessence Int 1993; 24(9): 618-631.

21 Tam LE, Pilliar RM. Effects of dentin surface treatments on the fracture toughness and tensile bond strength of a dentin-composite adhesive interface. J Dent Res 1994; 73(9): 1530-1538.

22 Soares CJ, Pizi EC, Fonseca RB et al. Influence of root embedment material and periodontal ligament simulation on fracture resistance tests. Braz Oral Res 2005; 19(1): 11-16.

23 Juloski J, Radovic I, Goracci C et al. Ferrule effect: a literature review. J Endod 2012 38(1): 11-19.

24 Akkayan B. An in vitro study evaluating the effect of ferrule length on fracture resistance of endodontically treated teeth restored with fiber-reinforced and zirconia dowel systems. J Prosthet Dent 2004; 92(2): 155-162.

25 Pereira JR, de Ornelas F, Conti PC et al. Effect of a crown ferrule on the fracture resistance of endodontically treated teeth restored with prefabricated posts. $J$ Prosthet Dent 2006; 95(1): 50-54.

26 Fragou $\mathrm{T}$, Tortopidis D, Kontonasaki $\mathrm{E}$ et al. The effect of ferrule on the fracture mode of endodontically treated canines restored with fibre posts and metal-ceramic or allceramic crowns. J Dent 2012; 40(4): 276-285.

This work is licensed under a Creative Commons Attribution-NonCommercial-NoDerivative Works 3.0 Unported License. To view a copy of this license, visit http:// creativecommons.org/licenses/by-nc-nd/3.0 